
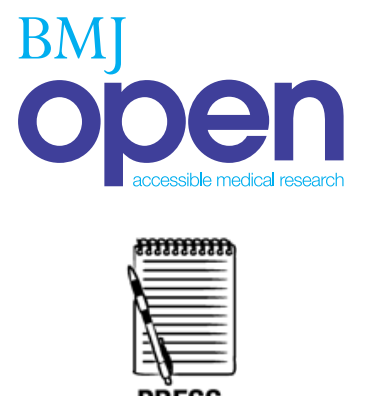

PRESS

RELEASE

\title{
Impact of a reduced red and processed meat dietary pattern on disease risks and greenhouse gas emissions in the UK: a modelling study
}

\author{
Louise M Aston, James N Smith, John W Powles
}

To cite: Aston LM, Smith JN, Powles JW. Impact of a reduced red and processed meat dietary pattern on disease risks and greenhouse gas emissions in the UK: a modelling study. BMJ Open 2012;2:e01072. doi:10. 1136/bmjopen-2012-001072

- Prepublication history and additional appendix for this paper are available online. To view these files please visit the journal online (http://dx. doi.org/10.1136/ bmjopen-2011-001072).

Received 29 March 2012 Accepted 2 July 2012

This final article is available for use under the terms of the Creative Commons Attribution Non-Commercial 2.0 Licence; see http://bmjopen.bmj.com

Department of Public Health and Primary Care, Cambridge, Institute of Public Health, University of Cambridge, Cambridge, UK

Correspondence to Dr Louise M Aston; louise.aston@cantab.net

\section{ABSTRACT}

Objectives: Consumption of red and processed meat (RPM) is a leading contributor to greenhouse gas (GHG) emissions, and high intakes of these foods increase the risks of several leading chronic diseases. The aim of this study was to use newly derived estimates of habitual meat intakes in UK adults to assess potential co-benefits to health and the environment from reduced RPM consumption.

Design: Modelling study using dietary intake data from the National Diet and Nutrition Survey of British Adults.

Setting: British general population.

Methods: Respondents were divided into fifths by energy-adjusted RPM intakes, with vegetarians constituting a sixth stratum. GHG emitted in supplying the diets of each stratum was estimated using data from life-cycle analyses. A feasible counterfactual UK population was specified, in which the proportion of vegetarians measured in the survey population doubled, and the remainder adopted the dietary pattern of the lowest fifth of RPM consumers.

Outcome measures: Reductions in risks of coronary heart disease, diabetes and colorectal cancer, and GHG emissions, under the counterfactual.

Results: Habitual RPM intakes were 2.5 times higher in the top compared with the bottom fifth of consumers. Under the counterfactual, statistically significant reductions in population aggregate risks ranged from $3.2 \%(95 \% \mathrm{Cl} 1.9$ to 4.7$)$ for diabetes in women to $12.2 \%$ (6.4 to 18.0) for colorectal cancer in men, with those moving from the highest to lowest consumption levels gaining about twice these averages. The expected reduction in $\mathrm{GHG}$ emissions was 0.45 tonnes $\mathrm{CO}_{2}$ equivalent/person/year, about $3 \%$ of the current total, giving a reduction across the UK population of 27.8 million tonnes/year.

Conclusions: Reduced consumption of RPM would bring multiple benefits to health and environment.

\section{INTRODUCTION}

Climate change is 'the biggest global health threat of the 21st century', and appropriately chosen mitigation policies could 'bring significant immediate co-benefits for population health and well-being'. ${ }^{2}$

\section{ARTICLE SUMMARY}

\section{Article focus}

- Consumption of RPM is a leading contributor to GHG emissions.

- High intakes of RPMs increase the risks of several leading chronic diseases.

- This research identifies a low RPM dietary pattern that is already followed by a substantial fraction of the UK population and estimates health and environmental benefits that would result from its general adoption.

Key messages

- Habitual RPM intakes are 2.5 times higher in the top compared with the bottom fifth of the UK consumers.

- Sustained dietary intakes at a counterfactual reduced level in the UK population would materially reduce incidence of coronary heart disease, diabetes mellitus and colorectal cancer, by $3 \%-12 \%$.

- The predicted reduction in UK food- and drinkassociated GHG emissions would equate to almost 28 million tonnes of $\mathrm{CO}_{2}$ equivalent/year across the population.

Strengths and limitations of this study

- This research uses a food-based approach, taking intake-risk associations from meta-analyses rather than assuming the mechanisms by which the foods influence disease risk.

- The dietary data were collected a decade ago; however, the headline results from a more recent national dietary survey reveal that intakes of all meat categories were broadly similar, although slightly higher in $2008 / 2009$ than in $2000 / 2001$.

Food and drink account for around one third of total greenhouse gas (GHG) emissions attributable to the UK consumers (when contributions from land-use change for agriculture are included). Around half of these emissions are 'embedded' in imports. Livestock products are particularly GHG intensive, with the Food and Agriculture Organisation attributing $18 \%$ of total global 
GHG emissions to these (when contributions from land use and land-use change are included). ${ }^{4}$ Although emissions can be reduced by changing production methods, savings achieved will not be sufficient to offset the effects of rising global demand, and radical departures from 'business as usual' trajectories will be needed to prevent global GHG emissions from livestock production rising unsustainably. ${ }^{5}{ }^{6}$ Even when food imports to the UK are ignored, failure to reduce domestic agricultural emissions will risk making the government's 2050 target for an $80 \%$ reduction in total UK-based GHG emissions 'unattainable'. ${ }^{7}$ Considering only the final food products, the UK is approximately $50 \%$ to $90 \%$ self-sufficient in livestock production (see web appendix). However, total GHG emissions arising from the full life-cycles of livestock food products are much bigger because of the overseas emissions associated with the large quantity of cereals and soy imported to feed animals raised in the UK.

Recent large meta-analyses ${ }^{8-10}$ have found significant increases in risk of coronary heart disease (CHD), type 2 diabetes and colorectal cancer with increased intake of processed meat (risk increases of $42 \%, 19 \%$ and $18 \%$, respectively, per $50 \mathrm{~g}$ increase per day). A significant increase in colorectal cancer risk has also been shown with increased intake of red meat $(17 \% / 100 \mathrm{~g}$ increase per day).

Here, we estimate the co-benefits to health and climate change mitigation if, in the UK, high consumers of red and processed meat (RPM) were to adopt the dietary patterns of current low consumers. We estimate the reductions in GHG emissions using published life-cycle analyses of different foods and predict health benefits using published associations of RPM intakes with incidence of CHD, diabetes mellitus and colorectal cancer from recent meta-analyses. Together, these diseases accounted for almost $12 \%$ of the total disease burden in the UK in $2004 .^{11}$

\section{METHODS}

\section{Dietary measurements}

Meat intakes have been estimated from the 2000/2001 British National Diet and Nutrition Survey (NDNS), which collected 7 days of weighed dietary records from a sample of 1724 respondents aged $19-64$ years. ${ }^{12}$ As previous reports from this source had not separately identified the meat content of composite meat-containing dishes, we derived new estimates by systematically recoding the original records. ${ }^{13}$ Meats were classified as (unprocessed) red, processed or white, and all foods were allocated to one of 45 food categories, designed to be relatively homogeneous in both their nutritional characteristics and the GHG emissions arising from their supply (table 1, which also includes the operational definitions of red, white and processed meat).

Intakes of each type of meat were adjusted for total energy intake (in grams/megajoule). The NDNS sample was then split by sex and stratified on the basis of average daily intakes of RPM. Self-declared vegetarians $(2.3 \%$ of men, $6.2 \%$ of women) were allocated to their own stratum. ${ }^{16}$ Remaining respondents were then ranked by average daily RPM intake and divided into fifths (F1 being lowest consumers, F5 highest). Mean RPM intakes for each of the resulting six sex-specific strata were standardised to the sex-specific mean energy intake in the total sample.

Among non-vegetarians, marked within-person variability existed in daily intakes of RPM over the 7-day recording period. As a consequence, the differences between strata created on the basis of just 7 days of observation were substantially greater than the differences that would have resulted had it been possible to create strata using information on each individual's usual (long-term average) intake. A method for correcting this inflation of between-stratum differences has been described elsewhere. ${ }^{13}$ In brief, sex-specific ratios of between- and within-person variances for energy-adjusted RPM intakes (in grams/megajoule) were used to derive sex-specific correction factors according to the following equation:

$$
\frac{S_{\text {between }}^{2}}{S_{\text {between }}^{2}+\frac{S_{\text {within }}^{2}}{7}} .
$$

These correction factors $(0.622$ in men and 0.542 in women) were used to 'shrink' the differences between each stratum's initial estimated mean and the sexspecific grand mean in order to estimate expected mean usual intakes for each stratum - as though they had been created on the basis of usual intakes rather than on intakes observed over just 7 days. For self-reported vegetarians, recorded intakes of RPM (which were not all null) were taken as the best estimates of usual intakes.

Mean energy-standardised intakes of all the 45 food categories were then calculated for each stratum. Stratum F1 was taken to exemplify a 'climate-friendly' low RPM dietary pattern. Key food and nutrient intakes plus health, behavioural and socio-demographic variables across these strata are described elsewhere. ${ }^{13}$

\section{Assignment of GHG emissions to food categories}

Emissions (shown in table 1) are expressed as kilograms of $\mathrm{CO}_{2}$ equivalent $\left(\mathrm{CO}_{2}\right.$-e) $\mathrm{GHG}$ resulting from all steps involved in making a given weight of food available for human consumption. Published values determined by life-cycle analyses were identified and used to estimate average emissions for each of the 45 food categories. ${ }^{14} 15$ Because emissions vary with system and country of production, weighted averages were calculated for meats according to proportions imported or produced in the UK under various systems. In the absence of data, processed meats were ascribed the values of equivalent unprocessed meats. Values for similar foods were interpolated where data were lacking. For the residual 'miscellaneous' category, the mean of all non-meat 
non-beverage categories was applied (further details in web appendix).

\section{Specification of a counterfactual diet}

A 'feasible alternative' ${ }^{17}$ counterfactual distribution of diets was specified as one in which the proportions of vegetarians in each sex doubled and the remainder of the population adopted the average dietary pattern of F1. All else was assumed to remain equal. Calculations were based on data for persons aged 19-64 years. Estimates for Britain in 2000/2001 were assumed to be generalisable to the UK over the following decade to the present day.

Changes in meat-related disease risks with the counterfactual intakes

Risk relationships for RPM intakes and CHD, diabetes mellitus and colorectal cancer were taken from published meta-analyses, presented in table $2 .^{8-10}$ The $\log$ of the RRs was assumed to be linearly related to absolute intakes across the full range of exposures in the data set, including the low (but not null) RPM intakes

Table 1 Greenhouse gas emissions, expressed as $\mathrm{CO}_{2}$ equivalents/kg food produced for consumption in the UK ${ }^{*}$

\begin{tabular}{|c|c|c|c|c|}
\hline & Food category & $\begin{array}{l}\text { GHG emissions } \\
(\mathbf{k g ~ C O}-\mathrm{e} / \mathbf{k g})\end{array}$ & Inclusions/notes & Source \\
\hline \multicolumn{5}{|c|}{ Unprocessed meat } \\
\hline 1 & Beef & 30.00 & & DEFRA $^{14}$ \\
\hline 2 & Lamb & 50.00 & & DEFRA $^{14}$ \\
\hline 3 & Pork & 10.00 & & DEFRA $^{14}$ \\
\hline 4 & Other red meat $\dagger$ & 30.00 & Venison, goat & Mean beef/pork/lamb \\
\hline 5 & White meat $\neq$ & 4.00 & Chicken, turkey, game birds & DEFRA $^{14}$ \\
\hline 6 & Other birds & 5.32 & Duck, goose & DEFRA $^{14}$ \\
\hline \multicolumn{5}{|c|}{ Processed meat $\S$} \\
\hline 7 & Processed beef & 30.00 & & $=$ Beef \\
\hline 8 & Processed pork & 10.00 & Sausage meat, bacon, ham & $=$ Pork \\
\hline 9 & Processed white meat & 4.00 & & $=$ White meat \\
\hline \multicolumn{5}{|c|}{ s } \\
\hline 10 & Fresh fish/shellfish & 2.60 & & Wallen et $a l^{15}$ \\
\hline 11 & Frozen fish & 6.50 & & Wallen et $a l^{15}$ \\
\hline \multicolumn{5}{|c|}{ Dairy/eggs } \\
\hline 12 & Milk & 1.30 & Yoghurt, cream, custard & DEFRA $^{14}$ \\
\hline 13 & Cheese & 9.80 & & Wallen et $a l^{15}$ \\
\hline 14 & Ice cream & 0.64 & & Wallen et $a l^{15}$ \\
\hline 15 & Egg & 3.00 & & DEFRA $^{14}$ \\
\hline \multicolumn{5}{|c|}{ Starchy staples } \\
\hline 16 & Bread & 0.73 & & DEFRA $^{14}$ \\
\hline 17 & Breakfast cereal & 1.00 & & Wallen et $a l^{15}$ \\
\hline 18 & Pasta & 0.81 & & Wallen et $a l^{15}$ \\
\hline 19 & Rice & 1.68 & & Wallen et $a l^{15}$ \\
\hline 20 & Unprocessed potato & 0.16 & & DEFRA $^{14}$ \\
\hline 21 & Frozen potato & 0.57 & & Wallen et $a l^{15}$ \\
\hline 22 & Other potato products & 2.37 & & Wallen et $a l^{15}$ \\
\hline 23 & Flour/other grains & 1.00 & & Wallen et $a l^{15}$ \\
\hline \multicolumn{5}{|c|}{ Fruit and vegetables } \\
\hline 24 & Vegetables (1) & 0.50 & Roots, onions, brassicas & Wallen et $a l^{15}$ \\
\hline 25 & Vegetables (2) & 3.30 & All other, including salad & Wallen et $a l^{15}$ \\
\hline 26 & Pulses & 0.64 & Dried/tinned & Wallen et $a l^{15}$ \\
\hline 27 & Tomato $^{g}$ & 2.00 & Including tinned & DEFRA $^{14}$ \\
\hline 28 & Fruit & 0.40 & All & Wallen et $a l^{15}$ \\
\hline \multicolumn{5}{|c|}{ Fats } \\
\hline 29 & Butter & 0.98 & & Wallen et $a l^{15}$ \\
\hline 30 & Margarine & 2.12 & & Wallen et $a l^{15}$ \\
\hline 31 & Cooking oil & 3.53 & & Wallen et $a l^{15}$ \\
\hline \multicolumn{5}{|c|}{ Other } \\
\hline 32 & Crispbread/biscuits & 2.65 & & Wallen et $a l^{15}$ \\
\hline 33 & Buns/cakes & 0.91 & & Wallen et $a l^{15}$ \\
\hline 34 & Chocolate/sweets & 1.80 & & Wallen et $a l^{15}$ \\
\hline 35 & Sugar/honey/treacle & 4.18 & & Wallen et $a l^{15}$ \\
\hline 36 & Jam/marmalade & 0.81 & Including chutneys & Wallen et $a l^{15}$ \\
\hline
\end{tabular}




\begin{tabular}{|c|c|c|c|c|}
\hline & Food category & $\begin{array}{l}\text { GHG emissions } \\
\text { (kg CO} 2-e / k g)\end{array}$ & Inclusions/notes & Source \\
\hline \multicolumn{5}{|c|}{ Beverages } \\
\hline 37 & Soft beverages & 0.56 & & Wallen et $a l^{15}$ \\
\hline 38 & Mineral water & 0.56 & & $=$ Soft beverages \\
\hline 39 & Alcoholic beverages & 0.56 & & $=$ Soft beverages \\
\hline 40 & Fruit juice/syrup & 0.99 & Including cordials & Wallen et $a l^{15}$ \\
\hline 41 & Coffee & 33.00 & & DEFRA $^{14}$ \\
\hline 42 & Tea & 4.10 & Including herbal tea & DEFRA $^{14}$ \\
\hline 43 & Cocoa & 210.00 & Including hot chocolate & DEFRA $^{14}$ \\
\hline 44 & Tap water & 0.00 & Including that in foods & No data \\
\hline 45 & Miscellaneous & 1.85 & All other & Mean of all \\
\hline \multicolumn{5}{|c|}{$\begin{array}{l}\text { Further details in web appendix: assumptions and methods used in the derivation of greenhouse gas emissions from food produced for the UK } \\
\text { consumers. } \\
\text { `Emission estimates are preferentially based on life-cycle analyses. Where emissions vary by production system within and beyond the UK, } \\
\text { values are averages weighted on contributions to the UK food supply. } \\
\text { The following definitions were used, consistent those used in the meta-analyses of intake-risk associations: †Red meat as beef, veal, pork, } \\
\text { lamb, mutton and goat, either fresh, minced (including hamburgers) or frozen, but unprocessed other than by cooking with heat. Although } \\
\text { processed meats were primarily red meats, the term 'red meat' has been used in this report to refer to 'unprocessed red meat', unless otherwise } \\
\text { specified. } \text { White meat as meat from poultry, fresh, minced or frozen, but unprocessed other than by cooking with heat. } \S \text { Processed meat as } \\
\text { meat preserved by smoking, curing, salting or addition of nitrates, nitrites or other preservatives. Under this definition, processed meats were } \\
\text { primarily red, but included white meats, and included ham, bacon, pastrami, salami, sausages and processed deli or luncheon meats. }\end{array}$} \\
\hline
\end{tabular}

reported by self-declared vegetarians. Stratum-specific RRs were used to estimate proportional changes in aggregated population risks. These 'potential impact fractions' (PIF) were estimated separately for each sex, using the following equation ${ }^{18}$ : and summing resulting values. Estimated habitual intakes were used for RPMs; however, as the proportional changes to other food categories (after adjustment of meat intakes from measured to estimated habitual) were negligible $(<3 \%)$, values derived from reported intakes

$$
\begin{gathered}
\mathrm{PIF}=\frac{\text { current aggregate risk }- \text { aggregate risk under counterfactual }}{\text { current aggregate risk }} \\
=\frac{\sum \mathrm{p}_{1 \mathrm{i}} \mathrm{PR}_{\mathrm{i}}-\sum \mathrm{p}_{2 \mathrm{i}} \mathrm{PR}_{\mathrm{i}}}{\sum \mathrm{p}_{1 \mathrm{i}} \mathrm{PR}_{\mathrm{i}}}
\end{gathered}
$$

where $\mathrm{p}$ refers to the proportion of the population in a given stratum, $\mathrm{i}$ identifies the stratum and 1 and 2 identify the current and counterfactual intakes, respectively. An overall PIF for each disease was calculated as the simple average of the values for men and women. Effects of reduced intakes of RPM on colorectal cancer risk were assumed to be independent so that, for a given disease, the combined effect of both changes was estimated as: $\left(\left(1-\mathrm{PIF}_{1}\right) \times\left(1-\mathrm{PIF}_{2}\right)\right)$. This proportional change was then applied to the WHO estimates for disease burdens in the UK for 2004 to give a population aggregate risk reduction for the UK. ${ }^{11}$ Proportional risk reductions were also estimated for the hypothetical scenario of reducing RPM from the mean level for F5 to a sustained intake at the mean for F1.

\section{Estimation of GHG emissions}

Diet-attributable GHG emissions were estimated for each stratum by multiplying mean intakes of each of the 45 food categories by their average emission value (table 1) were used for these. Resulting dietary emissions estimates were energy adjusted using the mean energy intake in the stratum and standardised to the mean sexspecific energy intake in the overall sample.

Diet-attributable GHG emissions under the counterfactual were calculated for each sex as weighted means of strata V and F1 (proportions in V doubling and F1 intake applied to all non-vegetarians). The overall value was calculated as the simple average of means for each sex. The difference between counterfactual and current emissions values gave the expected average reduction in emissions from the specified changes in measured dietary intakes at 19-64 years. These were then adjusted for average energy requirements in the total population relative to the study sample (which was restricted to ages 19-64 years). This adjustment factor was estimated at $0.93{ }^{19}$ Finally, the change in emissions based on measured intakes was rescaled to the level of the food supply supporting the measured intakes. This was based on the FAO Food Balance Sheet estimates, which 
Table 2 Relative risks (RRs) of incident coronary heart disease, diabetes mellitus and colorectal cancer for differences of $100 \mathrm{~g} /$ day usual intakes of red and $50 \mathrm{~g} /$ day of usual intakes of processed meat from two meta-analyses

\begin{tabular}{llll}
\hline Exposure & Disease & RR $(95 \%$ Cl) & Meta-analy \\
\hline $\begin{array}{l}\text { Red meat* } \\
\text { (RR per } 100 \mathrm{~g} / \text { day })\end{array}$ & $\begin{array}{l}\text { Coronary } \\
\text { heart disease }\end{array}$ & $1.00(0.81$ to 1.23$)$ & Micha et al \\
& & &
\end{tabular}

\section{Comments}

Based on four estimates, most controlled for total energy intake. No between-study heterogeneity or publication bias was evident. The range of exposures across all included studies (means in lowest/highest categories) was $15.7-118.6 \mathrm{~g} /$ day.

Diabetes mellitus $1.16(0.92$ to 1.46$) \quad$ Micha et $a l^{10}$

Based on five estimates, most controlled for total energy intake. No between-study heterogeneity or publication bias was evident. The range of exposures across all included studies (means in lowest/highest categories) was $15.7-118.6 \mathrm{~g} /$ day.

Colorectal cancer $1.17(1.05$ to 1.31$) \quad$ WCRF/AICR ${ }^{9}$

Based on eight cohort studies, most controlled for total energy intake. There was no evidence of heterogeneity was present, and a random-effects model was used. There were insufficient studies to check for publication bias. Intakes per category spanned the range 1 to $>200 \mathrm{~g} /$ day.

$\begin{array}{llll}\text { Processed meat } \dagger & \text { Coronary } & 1.42(1.07 \text { to } 1.89) & \text { Micha et al } \\ \text { (RR per } 50 \mathrm{~g} / \text { day }) & \text { heart disease }\end{array}$
Based on six estimates, most controlled for total energy intake. Between-study heterogeneity and publication bias were evident; sensitivity analysis did not significantly change the outcome, and a random-effects model was used. The range of exposures across all included studies (means in lowest/highest categories) was $2.9-40.7 \mathrm{~g} /$ day.

Diabetes mellitus $1.19(1.11$ to 1.27$) \quad$ Micha et ald Based on six estimates, most controlled for total dietary energy. Some heterogeneity was evident, but publication bias was not; sensitivity analysis did not significantly change the outcome, and a random-effects model was used. The range of exposures across all studies (means in lowest/highest categories) was $2.9-40.7 \mathrm{~g} /$ day.

Colorectal cancer $1.18(1.10$ to 1.28$) \quad$ WCRF/AICR ${ }^{9}$

Based on nine cohort studies, most controlled for total energy intake. Low heterogeneity was present, and a randomeffects model was used. Publication bias was not evident. Intakes per category spanned the range 1 to $>100 \mathrm{~g} /$ day.

${ }^{*}$ Red meat as beef, veal, pork, lamb, mutton and goat, either fresh, minced (including hamburgers) or frozen, but unprocessed other than by cooking with heat. Although processed meats were primarily red meats, the term 'red meat' has been used in this report to refer to 'unprocessed red meat', unless otherwise specified.

†Processed meat as meat preserved by smoking, curing, salting or addition of nitrates, nitrites or other preservatives. Under this definition, processed meats were primarily red, but included white meats, and included ham, bacon, pastrami, salami, sausages and processed deli or luncheon meats.

give total meat available for consumption in Britain as $219 \mathrm{~g} /$ person/day compared with the measured intakes of $104 \mathrm{~g} /$ person/day. This ratio for meats was used as an estimate for inflation of total dietary GHG emissions, although it is accepted that wastage varies between food groups. No attempt was made to model the effects of reducing waste.

\section{RESULTS}

RPM intakes show marked heterogeneity across the British population, with habitual intakes around 2.5 times higher in the top (F5) than in the bottom (F1) fifth of non-vegetarians. Under our counterfactual, $4.7 \%$ of men and $12.3 \%$ of women were vegetarian and the remainder adopted the sex-specific dietary pattern of F1. 
Figure 1 Reported and estimated habitual intakes of red and processed meat across strata based on energy-adjusted red and processed meat intake (mean and $95 \% \mathrm{Cl}$ ). Intakes in mean $\mathrm{g} / \mathrm{day}$ following energy adjustment and standardisation to sex-specific mean total reported energy intake. Overall factual and counterfactual (CF) mean intakes are also shown. $\mathrm{V}$, vegetarian; F1-5, fifths of energy-adjusted red and processed meat intake (F1=lowest intake).

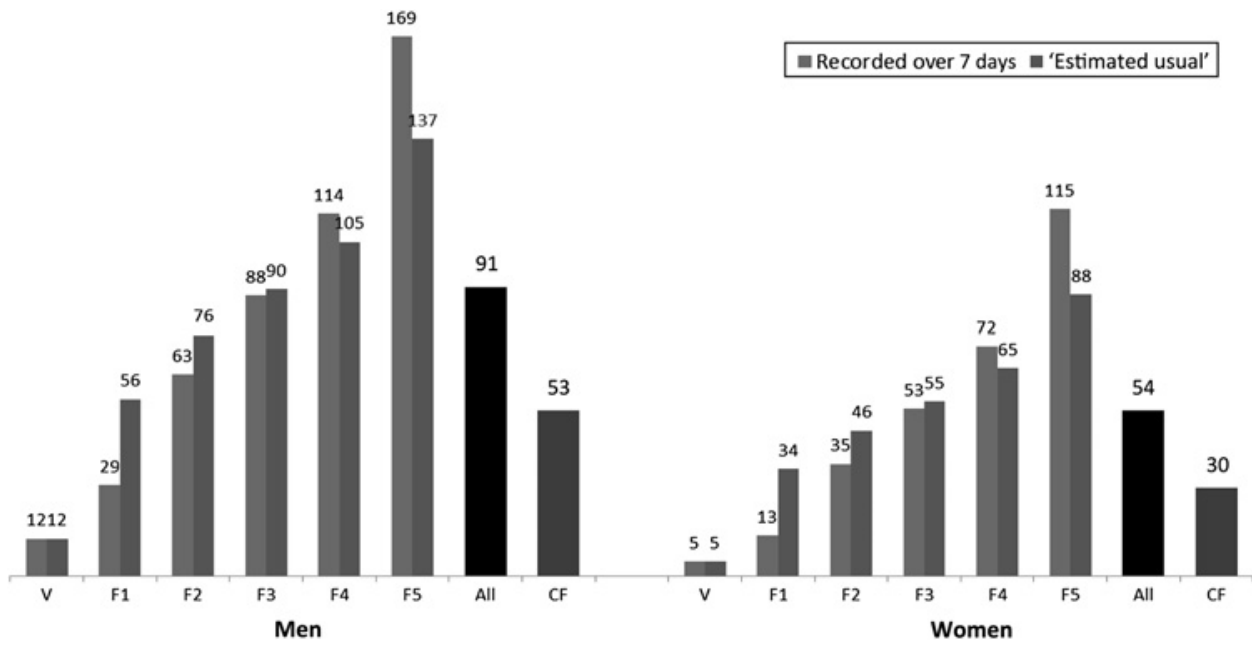

Average RPM intakes were reduced from 91 to $53 \mathrm{~g} /$ day in men and from 54 to $30 \mathrm{~g} /$ day in women $(42 \%$ and $44 \%$ reductions, respectively), as shown in figure 1.

\section{Changes in disease risks}

Assuming epidemiologically observed risk associations are causal and independent, statistically significant risk reductions for the three diseases of interest would range from $3.2 \%$ to $12.2 \%$ under the counterfactual scenario (see table 3). Benefits would be greatest in those with the highest current intakes (F5; see table 4).

\section{Changes in GHG emissions}

Total daily GHG emissions attributable to measured

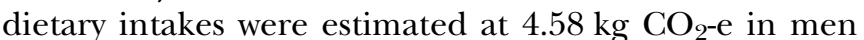
and $3.34 \mathrm{~kg} \mathrm{CO}$-e in women (unweighted mean $3.96 \mathrm{~kg}$ $\left.\mathrm{CO}_{2}-\mathrm{e}\right)$. The sex difference disappeared when emissions were expressed per megajoule of dietary energy $(0.47 \mathrm{~kg}$ $\mathrm{CO}_{2}-\mathrm{e} / \mathrm{MJ}$ in men, $0.49 \mathrm{~kg} \mathrm{CO}_{2}-\mathrm{e} / \mathrm{MJ}$ in women). Red meat intake accounted for $31 \%$ of dietary $\mathrm{CO}_{2}$-e emissions in men and $27 \%$ in women, with processed meat accounting for an additional $10 \%$ and $8 \%$ in men and women, respectively.

$\mathrm{CO}_{2}$-e emissions attributable to diet are shown for each stratum in figure 2. Emissions for men increased by one third from F1 to F5 and for women by one quarter. Emissions attributable to dietary constituents other than RPM were relatively constant across strata.

Diet-related emissions, calculated on the basis of intakes, were reduced by $0.47 \mathrm{~kg} \mathrm{CO}_{2}-\mathrm{e} /$ person/day (or $12 \%$ ) to $3.96 \mathrm{~kg} \mathrm{CO}-\mathrm{e} /$ person/day in men and $3.02 \mathrm{~kg}$ $\mathrm{CO}_{2}-\mathrm{e} /$ person/day in women. Scaling this estimate up to the food supplies supporting these intakes increases the expected reduction to $1.23 \mathrm{~kg} \mathrm{CO}_{2}-\mathrm{e} /$ person/day or 0.45 tonnes/person/year. For the 2009 UK population of 61792000 , this amounts to a total GHG reduction of 27.8 million tonnes/year.

\section{DISCUSSION}

We have identified a low RPM dietary pattern that is already followed by a substantial fraction of the UK population and estimated the health and environmental benefits that would result from its general adoption. Although the dietary intake data used here were collected a decade ago, the headline results from a more recent NDNS (fieldwork carried out 2008/2009) reveal that intakes of all meat categories were broadly similar, although slightly higher than in $2000 / 2001 .^{20}$ This indicates that our estimates remain relevant and may even be conservative and highlights the need for action

Table 3 Predicted reductions (\%) in population risks of coronary heart disease, diabetes and colorectal cancer from sustained exposure at counterfactual intakes of red and processed meat and both (assuming independence of effects)

$\begin{array}{lll}\text { Red meat } & \text { Processed meat } & \text { Red and processed meat } \\ \% \text { Risk change }\left(95 \% \mathrm{UI}^{*}\right) & \% \text { Risk change }\left(95 \% \mathrm{UI}^{\star}\right) & \% \text { Risk change }\left(95 \% \mathrm{UI}^{\star}\right)\end{array}$

\begin{tabular}{llll}
\hline $\begin{array}{l}\text { Coronary heart disease } \\
\text { Men }\end{array}$ & $0.0 \dagger(-10.4$ to 11.0$)$ & $-9.7(-1.8$ to -18.1$)$ & $-9.7 \dagger(3.6$ to -22.0$)$ \\
$\quad$ Women & $0.0 \dagger(6.4$ to -6.2$)$ & $-6.4(-1.2$ to -11.9$)$ & $-6.4 \dagger(1.8$ to -14.3$)$ \\
$\begin{array}{ll}\text { Diabetes mellitus } \\
\text { Men }\end{array}$ & $-7.5 \dagger(4.2$ to -18.6$)$ & $-4.9(-2.8$ to -7.3$)$ & $-12.0 \dagger(4.5$ to -22.7$)$ \\
$\quad$ Women & $-4.5 \dagger(2.5$ to -11.5$)$ & $-3.2(-1.9$ to -4.7$)$ & $-7.5(-0.5$ to -14.5$)$ \\
Colorectal cancer & & & $-12.2(-6.4$ to -18.0$)$ \\
$\quad$ Men & $-7.9(-2.4$ to -13.5$)$ & $-4.6(-2.4$ to -7.2$)$ & $-7.7(-4.0$ to -11.3$)$ \\
$\quad$ Women & $-4.8(-1.4$ to -8.3$)$ & $-3.0(-1.6$ to -4.7$)$ &
\end{tabular}

*Uncertainty intervals estimated by Monte Carlo simulation, using @ Risk software (Palisade).

†Non-significant. 
Table 4 Predicted reductions (\%) in risks of coronary heart disease, diabetes and colorectal cancer for persons with usual intakes at the mean levels for F5 had they had sustained exposure at usual intakes for F1 of red and processed meat and both (assuming independence of effects)

\begin{tabular}{lll}
$\begin{array}{l}\text { Red meat } \\
\% \text { Risk change }(95 \% \text { UI*) }\end{array}$ & $\begin{array}{l}\text { Processed meat } \\
\% \text { Risk change (95\% UI*) }\end{array}$ & $\begin{array}{l}\text { Red plus processed meat } \\
\% \text { Risk change }\left(95 \% \mathrm{U} I^{*}\right)\end{array}$ \\
\hline
\end{tabular}

\section{Coronary heart disease}

\begin{tabular}{llll} 
Men & $0.0 \dagger(25.7$ to -20.4$)$ & $-20.6(-4.2$ to -35.1$)$ & $-20.6 \dagger(1.3$ to -37.0$)$ \\
Women & $0.0 \dagger(17.6$ to -14.7$)$ & $-11.0(-2.2$ to -20.0$)$ & $-11.1 \dagger(7.7$ to -26.7$)$ \\
$\begin{array}{l}\text { Diabetes mellitus } \\
\text { Men }\end{array}$ & $-14.9 \dagger(9.2$ to -33.8$)$ & $-10.5(-6.4$ to -15.7$)$ & $-24.1 \dagger(1.6$ to -41.7$)$ \\
$\begin{array}{l}\text { Women } \\
\text { Colorectal cancer }\end{array}$ & $-10.8 \dagger(6.6$ to -25.6$)$ & $-5.7(-3.3$ to -8.4$)$ & $-15.9 \dagger(0.9$ to -30.0$)$ \\
Men & $-15.7(-4.9$ to -25.6$)$ & $-10.3(-5.5$ to -15.5$)$ & $-24.4(-13.6$ to -34.1$)$ \\
Women & $-11.4(-3.4$ to -19.0$)$ & $-6.4(-2.8$ to -8.4$)$ & $-16.2(-8.4$ to -23.7$)$ \\
\hline
\end{tabular}

*Uncertainty intervals estimated by Monte Carlo simulation, using @ Risk software (Palisade).

†Non-significant.

to prevent further increases in intake in the UK population.

We estimate that sustained dietary intakes at our counterfactual levels would materially reduce incidence of CHD, diabetes mellitus and colorectal cancer. Our method for calculating changes in population aggregate risks could not allow for confounding on the outcome. ${ }^{21}$ Our point estimates for these reductions have associated uncertainties, which we have estimated using Monte Carlo simulation, although the RR estimates may still be more uncertain than we have assumed. Our estimates have been based on meta-analyses of a limited number of reports of the association between intakes of different types of meat and the chronic diseases of interest and are therefore highly dependent on these results. A more recent meta-analysis indicates that our results may be conservative for diabetes. ${ }^{22}$ This research, including over 440000 individuals, found a similar but statistically significant increase in risk of type 2 diabetes with unprocessed red meat intake (RR 1.19 (95\% CI 1.04 to

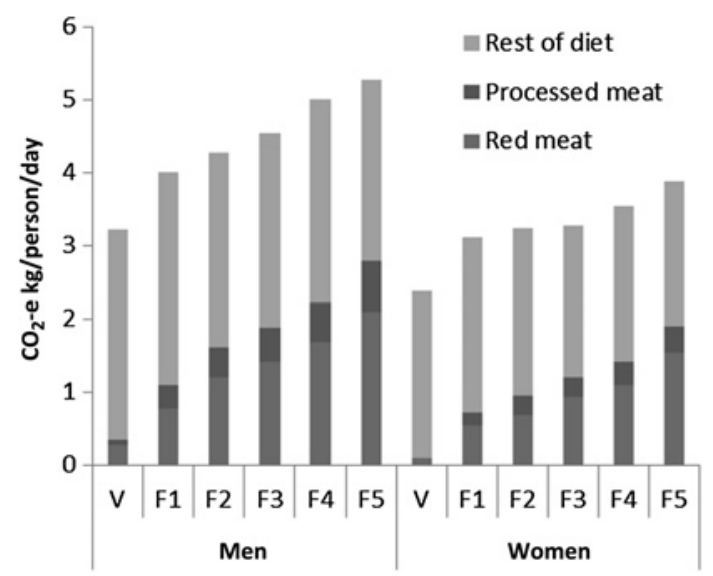

Figure 2 Diet-related standardised energy-adjusted CO2-e emissions according to dietary component across sex-specific categories of energy-adjusted red and processed meat intake (based on estimated habitual intake of red and processed meats). V, vegetarian; $\mathrm{F} 1-5$, fifths of energy-adjusted red and processed meat intake ( $\mathrm{F} 1=$ lowest intake)
1.37) per $100 \mathrm{~g}$ unprocessed red meat per day) but a far stronger association with processed meat than that used here (RR 1.51 (95\% CI 1.25 to 1.83 ) per $50 \mathrm{~g}$ processed meat per day). A recent update of the WCRF/AICR meta-analysis does not change the RR estimates given in that report and used in our analyses. ${ }^{23}$

Using meta-analyses of the association between intakes of different types of meat and the risks of vascular disease and diabetes, we have avoided simply regarding meat as a vehicle for dietary fats and assuming all associated risks to be mediated via effects on blood lipids. ${ }^{24}$ This food-based approach to assessing the health effects of meat is supported by the failure of epidemiological studies to confirm expected associations between intakes of unprocessed red meat and risk of CHD, by the differing patterns of epidemiological association with unprocessed and processed red meat and by the evidence that RPM intakes are associated with other vascular risk factors, notably blood pressure. ${ }^{25}{ }^{26}$ While we have only considered a limited range of diseases here, the incidence of stroke and a wider range of cancers could also be expected to decline. ${ }^{27}$

Using 2004 Global Burden of Disease estimates for the $\mathrm{UK}^{11}$ the reduction in health losses under the counterfactual would be 50960 disability-adjusted life-years (DALYs) per year for ischaemic heart disease, 5421 DALYs per year for diabetes and 13761 DALYs per year for colorectal cancer. If effects on these diseases were independent of each other, total reduction in DALYs would be 70142 /year, equivalent to almost $1 \%$ of health losses from all causes in the UK in 2004. These calculations are based on the assumptions that effects on incidence-based disease burdens are proportional to effects on incidence and that the results based on the diets of 19-64 year-olds are applicable to the over-65 population, where the majority of the disease burden lies.

The predicted reduction in GHG emissions would equate to a total saving in UK food- and drink-associated emissions of 27.8 million tonnes $\mathrm{CO}_{2}-\mathrm{e} /$ year across the 2009 UK population. To put this into context, the UK GHG 'footprint' has been estimated (using production- 
based accounts) at 10.16 tonnes $\mathrm{CO}_{2}$-e/person/year. ${ }^{28} 29$ Total emissions attributable to the UK consumers will exceed this by perhaps $30 \%-40 \%$ due to large net imports of embedded GHG. ${ }^{30}$ This implies that consumption-based emissions are over 14 tonnes $\mathrm{CO}_{2}-\mathrm{e} /$ person/year. Emissions reductions under the counterfactual therefore represent a saving of over $3 \%$ of this figure, a worthwhile amount given that climate change mitigation is going to require contributions from diverse sources.

Recent work for the UK Committee on Climate Change (CCC) has modelled the reductions in GHG emissions both in the UK and in overseas resulting from three specified dietary change scenarios. ${ }^{7} 31$ Under a scenario in which UK intake of livestock products was reduced by $50 \%$ (with a two-third reduction in all meat and the deficit replaced with plant-based foods), the reduction in GHG emissions was estimated to be 15.0 million tonnes $\mathrm{CO}_{2}$-e/year. In a second scenario, beef and sheep meat were replaced with pig and poultry, with no overall reduction in total meat intake, resulting in a reduction in GHG emissions of 6.3 million tonnes $\mathrm{CO}_{2}$-e/year. The dietary changes in the CCC scenarios were more extreme than the counterfactual dietary pattern taken here, with either a greater total reduction in meat or total elimination of beef and sheep meat. However, the GHG reductions estimated in this work were greater due to inflation to account for wasted food. While we made no attempt to model the impact of a reduction in waste, this demonstrates the great potential to make GHG savings even without major dietary changes through reducing waste. This approach, however, would not bring co-benefits to health.

We found that around one quarter of the UK population had habitual intakes of RPM below $55 \mathrm{~g} /$ day and $27 \mathrm{~g}$ /day for men and women, respectively, representing around two thirds $(62 \%)$ and one half $(51 \%)$ of their sex-specific means. Examination of the rest of the diet revealed that some, but far from all, of this reduction was offset by increased white meat intake, and remaining dietary substitution for RPM came from a wide variety of other sources. ${ }^{10}$ We have not considered beneficial effects from compensatory increases in other dietary components, especially fruit and vegetables and dietary fibre. Other assessments of the health effects of broadly similar dietary changes have found these beneficial effects to be of even greater magnitude than the reductions in harms. ${ }^{24}$ Recent estimation of the health effects of the CCC dietary scenarios has found that the greatest health gains were achieved when meat was replaced by fruits and vegetables. ${ }^{32}$ The influence of increases in these foods was far greater than health benefits attributable to reductions in salt consumption or changes in the fatty acid profile of the diets. When considering both the health and environmental effects of reducing RPM consumption therefore substitute foods are important, and clear advice should be given regarding these in order that benefits are maximised.
Intakes of RPM are socially patterned, especially in women. Forty-five per cent of low (F1) but only $29 \%$ of high (F5) RPM strata for women were in social class I or II and $41 \%$ versus $19 \%$ had formal education beyond $\mathrm{A}$ level. ${ }^{12}$ Although mainly outside the scope of this paper, it may also be noted that inequalities in health outcomes are produced by inequalities in health determinants, so a downward convergence of RPM intakes would be expected to yield a third benefit: a reduction in health inequalities. This is illustrated by the large potential risk reductions available to high consumers were they to converge down to the intakes of the low consumers.

Climate change mitigation is a far-future benefit that may not directly affect those who must make lifestyle changes now. It is therefore unlikely to be a strong motivator for change. In contrast, health benefits provide near-term rewards to individuals for climatefriendly changes and may thus 'nudge' humanity towards a sustainable future. Dietary recommendations should no longer be based on direct health effects alone. While the UK government has acknowledged the environmental impact of livestock production and is taking action with the industry to improve efficiency, ${ }^{33}$ changes in production will be insufficient alone to meet challenging emission reduction targets. Joint producer and consumer responsibility is needed, supported by the use of both production- and consumption-based GHG accounts. Averting dangerous climate change will require multiple changes at all levels of society, and the potential contribution of reduced RPM consumption should be addressed.

Contributors All authors contributed to conception and design of the study. Data analysis and interpretation were performed by LMA and JP. All authors contributed to manuscript preparation and have approved the submitted manuscript.

Funding Work contributing to this manuscript was carried out as part of the University of Cambridge MPhil in Public Health degree (LMA and JNS, supervised by JWP); degrees were funded by the NHS East of England Multi-Professional Deanery.

Competing interests None.

Provenance and peer review Not commissioned; externally peer reviewed.

Data sharing statement This research used the publicly available NDNS data set. GHG emissions were estimated from various published sources and are listed in the web appendix.

\section{REFERENCES}

1. Costello A, Abbas M, Allen A, et al. Managing the health effects of climate change: Lancet and University College London Institute for Global Health Commission. Lancet 2009;373:1693-733.

2. Garnett T. Cooking Up a Storm: Food, Greenhouse Gas Emissions and Our Changing Climate. Guildford: Food Climate Research Network, 2008.

3. Audsley E, Brander M, Chatterton J, et al. How Low Can We Go? An Assessment of Greenhouse Gas Emissions from the UK Food System and the Scope for Reduction by 2050. Godalming: WWF-UK, 2010.

4. Food and Agriculture Organisation. Livestock's Long Shadow: Environmental Issues and Options. Rome: FAO, 2006.

5. McMichael AJ, Powles JW, Butler CD, et al. Energy and health 5Food, livestock production, energy, climate change, and health. Lancet 2007;370:1253-63.

6. Erb KH, Haberl H, Krausmann K, et al. Eating the Planet: Feeding and Fuelling the World Sustainably, Fairly and Humanely-A Scoping 
Study. Commissioned by Compassion in World Farming and Friends of the Earth UK. Vienna: Institute of Social Ecology, 2009.

7. Committee on Climate Change. The Fourth Carbon Budget: Reducing Emissions through the 2020s. London: Committee on Climate Change, 2010. http://www.theccc.org.uk/reports/fourth-carbonbudget (accessed 28 Jun 2011).

8. WCRF/AICR. Food, Nutrition, Physical Activity and the Prevention of Cancer: a Global Perspective. Washington DC: AICR, 2007.

9. Norat T, Chan D, Lau R, et al. The Associations Between Food, Nutrition and Physical Activity and the Risk of Colorectal Cancer: WCRF/AICR Systematic Literature Review Continuous Update Project Report. Imperial College London: WCRF/AICR, 2010.

10. Micha R, Wallace S, Mozaffarian D. Red and processed meat consumption and risk of incident coronary heart disease, stroke, and diabetes mellitus: a systematic review and meta-analysis. Circulation 2010;121:2271-83.

11. WHO Global Health Observatory Data Repository. Death and DALY estimates for 2004 by cause for WHO member states. Geneva: WHO, 2009. http://apps. who.int/ghodata/?vid=10011 (accessed 20 Sep 2011).

12. Office for National Statistics. National Diet and Nutrition Survey: Adults Aged 19 to 64 years, 2000-2001 [computer file] SN: 5140. Colchester, Essex: UK Data Archive [distributor], 2005.

13. Aston LM, Smith JN, Powles JW. Meat intake in Britain in relation to other dietary components and to demographic and risk factor variables: analyses based on the National Diet and Nutrition Survey of 2000/2001. J Hum Nutr Diet. In press.

14. Department for Environment Food and Rural Affairs. Scenario Building to Test and Inform the Development of a BSI Method for Assessing GHG Emissions from Food. Research Project Final Report FO0404. London: DEFRA, 2009.

15. Wallen A, Brandt N, Wennersten R. Does the Swedish consumer's choice of food influence greenhouse gas emissions? Environ Sci Policy 2004;7:525-35.

16. Henderson L, Gregory J, Swann G. The National Diet and Nutrition Survey: adults aged 19 to 64 years. Volume 1: Types and quantities of foods consumed. Norwich: HMSO, 2002.

17. Murray CJL, Lopez AD. On the comparable quantification of health risks: lessons from the Global Burden of Disease study. Epidemiology 1999;10:594-605.

18. Ezzati M, Lopez AD, Rodgers A, et al. Selected major risk factors and global and regional burden of disease. Lancet 2002;360:1347-60.

19. Schofield WN. Predicting basal metabolic rate, new standards and review of previous work. Hum Nutr Clin Nutr 1985;39(S1):5-41.
20. Food Standards Agency. Tables - NDNS Headline results from Year 1 of the Rolling Programme (2008/9). FSA, 2010. http://www.food. gov.uk/science/dietarysurveys/ndnsdocuments/ndns0809year1 (accessed 15 Jul 2010).

21. Rockhill B, Newman B, Weinberg C. Use and misuse of population attributable fractions. Am J Public Health 1998;88:15-19.

22. Pan $A$, Sun $Q$, Bernstein $A M$, et al. Red meat consumption and risk of type 2 diabetes: 3 cohorts of US adults and an updates metaanalysis. Am J Clin Nutr 2011;94:1088-96.

23. Chan DS, Lau R, Aune D, et al. Red and processed meat and colorectal cancer incidence: meta-analysis of prospective studies. PLoS One 2011;6:e20456.

24. Scarborough $\mathrm{P}$, Noaham KE, Clarke D, et al. Modelling the impact of a healthy diet on cardiovascular disease and cancer mortality. J Epidemiol Community Health 2012;66:420-6.

25. Miura K, Greenland P, Stamler J, et al. Relation of vegetable, fruit, and meat intake to 7 -year blood pressure change in middle-aged men: the Chicago Western Electric Study. Am J Epidemiol 2004;159:572-80.

26. Steffen LM, Kroenke CH, Yu X, et al. Associations of plant food, dairy product, and meat intakes with 15-y incidence of elevated blood pressure in young black and white adults: the Coronary Artery Risk Development in Young Adults (CARDIA) Study. Am J Clin Nutr 2005;82:1169-77.

27. Friel S, Dangour AD, Garnett T, et al. Public health benefits of strategies to reduce greenhouse-gas emissions: food and agriculture. Lancet 2009;374:2016-25.

28. Department for Environment Food and Rural Affairs. The Environment in Your Pocket. Norwich: The Stationery Office, 2009.

29. Office for National Statistics. Population Estimates. 2010. http://www ons.gov/ons/rel/npp/national-population-projections/2010-basedprojections/index.html

30. Davis S, Caldeira K. Consumption-based accounting of $\mathrm{CO}_{2}$ emissions. Proc Natl Acad Sci U S A 2010;107:5687-92.

31. Audsley E, Angus A, Chatterton JC, et al. Food, land and greenhouse gases: The effect of changes in UK food consumption on land requirements and greenhouse gas emissions. Report for the Committee on Climate Change. Cranfield: Cranfield University, 2010.

32. Scarborough $\mathrm{P}$, Allender $\mathrm{S}$, Clarke $\mathrm{D}$, et al. Modelling the health impact of environmentally sustainable dietary scenarios in the UK. Eur J Clin Nutr 2012;66:710-15.

33. EBLEX. Change in the Air: The English Beef and Sheep Production Roadmap. Kenilworth: EBLEX, 2009. 